In 1948 it was noted that whatever the standard of dietary control there was little variation in food intake from day to day. In some patients there was a tendency for a reduction of food intake towards the end of the week, and this was assumed to indicate an element of financial difficulty before pay or pension day, especially as it was more obvious in patients with limited means. In complete contrast, in 1968 there were considerable fluctuations in intake from day to day, with no particular pattern discernible during the week. Some variability was noted even in those patients who, on average, were keeping close to the prescribed diet. The extreme example of such variation was in a diet which ranged from 1,265 to 2,850 calories per day within the week, the patient, perhaps surprisingly, was a woman aged 63 . Though these fluctuations may have an adverse effect on blood glucose levels they are in keeping with the variations observed in normal people, and are presumably related to the changing energy requirements from day to day. Booyens and McCance (1957) showed that in six normal subjects there was a wide range of daily food intake, the calorific intake varying from an average of 2,114 to 3,007 calories during a one-week or two-week period.

There are obviously many social and economic factors which influence a diabetic patient's ability and desire to follow dietary advice. One factor is the cost of the diabetic diet, and this was assessed in both Leeds surveys. In 1948 it was found that the average weekly cost of food for diabetics was $23 \mathrm{~s}$., while the average cost of food for the non-diabetic members of the same families was just over 10s. In 1968 the cost of an ideal diabetic diet, of the same calorific value as the average prescribed for the patients in the survey, was found to be $44 \mathrm{~s}$. 1d. This figure was calculated after a careful survey of the range of local retail prices. The probable average cost is not the arithmetical mean of the lowest and highest possible cost. It is unlikely that many patients would buy food at the highest prices and even more unlikely that they could buy all their food at the cheapest prices, for these were usually limited to one area within the city. We have therefore assumed, after reviewing the patients' records and the range of prices for each item of food, that the probable actual cost of each item was the minimum cost plus two-thirds of the difference between minimum and maximum costs.

In assessing the cost of the diets actually consumed it was found that many patients failed to identify their food in sufficient detail for a confident calculation to be made. In those cases where the information supplied was adequate the probable actual cost, on average, was $49 \mathrm{~s}$. $3 \mathrm{~d}$. Though the results of these calculations must be accepted with caution, they all indicate that the cost of food for diabetics is higher than for non-diabetics (38s. 4d.) (National Food Survey, 1968), and support the clinical finding that patients with low incomes continue to have difficulty in purchasing a correct diet.

We would like to acknowledge the help we received during this survey from all the patients who co-operated; Miss Boyle, senior lecturer in the department of nutrition and dietetics; the dietetic students at the Leeds College of Technology; Miss Conry, chief dietitian to the United Leeds Hospitals; and Miss Spence, secretary in the department of medicine.

\section{REFERENCES}

Bloom, A. (1967). Proceedings of the Royal Society of Medicine, 60, 149. Booyens, J., and McCance, R. A. (1957). Lancet, 1, 225.

National Food Survey (1966). Board of Trade fournal, 195, 922.

Tunbridge, R. E. (1949). British Medical fournal, 2, 70.

Tunbridge, R. E. (1953). Lancet, 2, 893.

\title{
Subclinical Neuropathy in Lead Workers
}

\section{J. CATTON, ${ }^{*}$ M.B., D.P.H. ; M. J. G. HARRISON, $\ddagger$ D.M., M.R.C.P. ; PAMELA M. FULLERTON, $\dagger$ D.M., M.R.C.P.}

$$
\text { G. KAZANTZIS, } \ \text { PH.D., M.R.C.P. }
$$

\section{$S^{n}$} ummary: Evidence is presented for a minimal defect of peripheral nerve function in a group of lead accumulator. workers without clinical evidence of a neurological lesion. Of the 19 men examined, 13 had blood levels above $80 \mu \mathrm{g} . / 100 \mathrm{ml}$. and seven had haemoglobin levels below $12 \mathrm{~g} . / 100 \mathrm{ml}$, showing that considerable exposure to lead was occurring.

\section{Introduction}

Exposure to lead is still an occupational hazard, and leadpoisoning remains the commonest notifiable industrial disease in Great Britain (Department of Health and Productivity, 1968). Lead palsy, at one time common, is now rare in clinical practice. It is possible, however, that exposed workers might develop minor degrees of peripheral nerve damage, insufficient to cause symptoms or signs. Lloyd Davies (1965) discussed the problem of subclinical damage in relation to other aspects of lead-poisoning.

* H.M. Divisional Medical Inspector of Factories, London.

† Consultant Neurologist, Middlesex Hospital, London W.1; Part-time Member, M.R.C. Toxicology Unit, Carshalton, Surrey.

¥ Registrar, Department of Neurology, Middlesex Hospital, London W.1. o Senior Lecturer in Social and Preventive Medicine, Middlesex Hospital, London W.1.
Experimentally a neuropathy can be produced in guineapigs by chronic lead intoxication (Gombault, 1880). The main pathological change in the peripheral nerve fibres consists of segmental demyelination and may be associated with pronounced slowing of nerve conduction velocity (Fullerton, 1966). There have been a few previous studies of nerve conduction velocity in lead workers, both with and without clinical evidence of toxicity. Delwaide and Chantraine (1965) investigated 12 patients and found that, even in the presence of considerable muscle wasting, motor conduction velocity was below the lower limit of normal in only one subject. Simpson, Seaton, and Adams (1964) also found normal motor conduction in a patient with a neurological disorder attributed to lead intoxication. On the other hand, in two other studies slight changes in conduction velocity were found in workers without any abnormal neurological symptoms or signs (Bergamini and Sibour, 1960; Sessa, Ferrari, and d'Amato, 1965). Thus slight reduction in conduction velocity has been found in lead workers on a few occasions, but changes comparable to those seen in guinea-pigs with lead neuropathy have not been described in man.

In view of continuing doubt about the nature of the peripheral nerve lesion in man and the level of exposure at which subclinical damage might occur, a further study of exposed workers has been carried out, a preliminary report of which has already appeared (Fullerton, 1969). 


\section{Subjects}

Nineteen men engaged in the manufacture of lead acid accumulators formed the subjects of the study. After leadpoisoning had been diagnosed in one worker with colic and anaemia a routine factory survey was performed by one of us (M.J.C.). As a result four more men were admitted to hospital with anaemia, found on investigation to be due to excessive lead absorption, making a total of five who were thus suspended from work. The remaining 14 lead workers volunteered for examination from the group surveyed. They were chosen on the basis of age under 45 and exposure to lead for more than three months, but no other criteria were used in their selection. Seventeen male hospital personnel of similar age distribution without industrial exposure to lead acted as controls.

\section{Methods}

Lateral popliteal nerve conduction studies were carried out with standard techniques. Skin temperature of the foot and leg were measured and a period of warming in hot water was allowed if necessary to ensure a temperature of at least $30^{\circ} \mathrm{C}$. over the foot and $32^{\circ} \mathrm{C}$. at the knee during the conduction studies. For estimating motor conduction velocity, muscle action potentials were recorded from extensor digitorum brevis through surface electrodes. One electrode was positioned over the muscle belly and the other over the tendon, the interelectrode distance being $4 \mathrm{~cm}$. The electrode position was adjusted to give the largest amplitude response to nerve stimulation. Motor conduction velocity was calculated from the difference in latency following stimulation of the nerve at the ankle and at the head of the fibula. The amplitude of the negative deflection of the muscle action potential above the baseline was also measured in each instance.

In some of the subjects a nerve action potential was recorded through subcutaneous needle electrodes placed close to the nerve at the head of the fibula during stimulation at the ankle, as described by Gilliatt, Goodman, and Willison (1961). Successive responses were superimposed photographically to improve the resolution of the potential. Its amplitude was measured, and conduction velocity of the fastest fibres contributing to the afferent volley was calculated by measuring the latency to the onset of the negative deflection.

\section{Results}

The duration of exposure to lead in the 19 workers was between five months and 13 years. The distribution of haemoglobin values and of blood lead concentration in this group when first seen is given in Table I. Seven men had haemoglobin values below $12 \mathrm{~g} . / 100 \mathrm{ml}$. and seven had blood lead concentrations above $120 \mu \mathrm{g} . / 100 \mathrm{ml}$. Two of the lead workers had symptoms related to their anaemia and three had a lead line on the gums. Inspection of the workplace confirmed that hygienic standards were poor. None of the lead workers had
TABLE I.-Haemoglobin and Blood Lead Levels in the Exposed Workers

\begin{tabular}{|c|c|c|c|c|c|c|c|c|}
\hline \multicolumn{4}{|c|}{$\begin{array}{c}\text { Haemoglobin } \\
\text { (g./100 ml. })\end{array}$} & $\begin{array}{l}\text { No. of } \\
\text { Men }\end{array}$ & \multicolumn{3}{|c|}{$\begin{array}{l}\text { Blood Lead } \\
(\mu \mathrm{g} . / 100 \mathrm{ml} .)\end{array}$} & $\begin{array}{l}\text { No. of } \\
\text { Men }\end{array}$ \\
\hline $\begin{array}{l}\text { Below } 12 . . \\
12-12 \cdot 9 . . \\
13 \text { and above }\end{array}$ & $\ddot{\cdots}$ & $\begin{array}{l}\cdots \\
\cdots\end{array}$ & $\because$ & $\begin{array}{r}7 \\
2 \\
10\end{array}$ & $\begin{array}{l}120 \text { and above } \\
80-119 \quad \ldots \\
40-79 \quad \ldots\end{array}$ & $\because$. & $\begin{array}{l}. \\
. .\end{array}$ & $\begin{array}{l}7 \\
6 \\
6\end{array}$ \\
\hline & & Total & $\because$ & 19 & & Total & 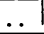 & 19 \\
\hline
\end{tabular}

symptoms or signs referable to the nervous system, nor any history of previous neurological illness. Their age distribution was' 19 to 44 years, with a mean of 26.8 years. The 17 men forming the control group also had a mean age of 26.8 years and were free of neurological disorder or any previous neurological illness.

The results of the electrophysiological studies are shown in Table II and Figs. 1 and 2. There was no difference in the maximal velocity of motor fibres or of fibres contributing to the afferent volley in the lead workers compared with the

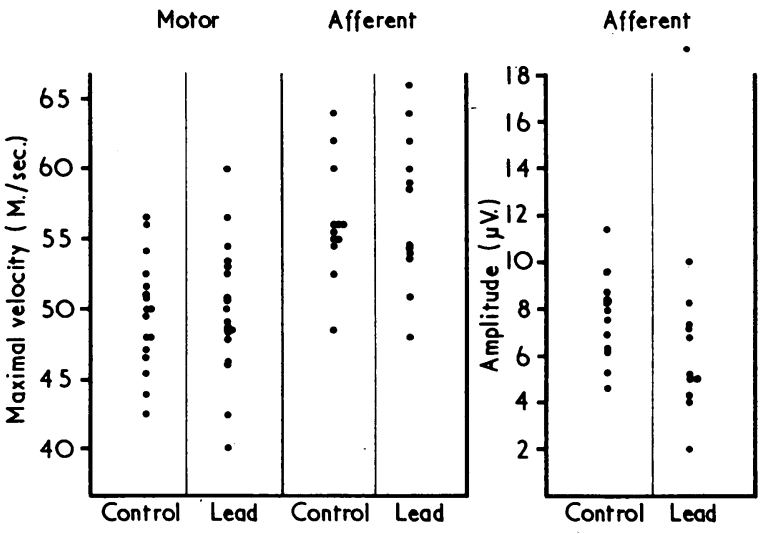

Fig. 1.-Lateral popliteal nerve conduction studies.

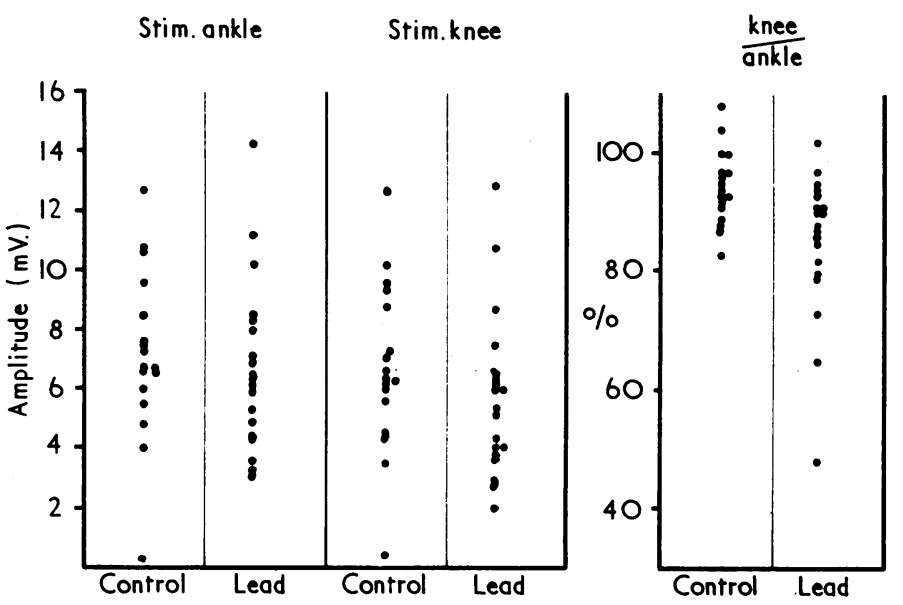

FIG. 2.-Amplitude of the negative phase of the muscle action potential recorded from extensor digitorum brevis.

TABle II.-Lateral Popliteal Nerve Conduction Studies on Lead-exposed Workers and Control Subjects

\begin{tabular}{|c|c|c|c|c|c|c|}
\hline & \multicolumn{2}{|c|}{$\begin{array}{l}\text { Maximal Velocity } \\
\mathrm{m} / \mathrm{sec} .\end{array}$} & \multirow{2}{*}{$\begin{array}{c}\text { Afferent } \\
\text { Amplitude } \\
(\mu \mathrm{V})\end{array}$} & \multicolumn{2}{|c|}{$\begin{array}{l}\text { Muscle } \\
\text { Action Potential } \\
\text { Amplitude }\end{array}$} & \multirow{2}{*}{$\begin{array}{c}\text { Muscle } \\
\text { Action Potential } \\
\text { Amplitude } \\
\text { Knee/Ankle } \\
\%\end{array}$} \\
\hline & Motor & Afferent & & $\begin{array}{l}\text { Ankle } \\
(\mathrm{mV})\end{array}$ & $\begin{array}{l}\text { Knee } \\
\text { (mV) }\end{array}$ & \\
\hline $\begin{array}{l}\text { Lead workers : } \\
\text { Mean } \\
\text { S.D. } \\
\text { Controls: }\end{array}$ & $\begin{array}{r}49 \cdot 87 \\
\pm 4 \cdot 69\end{array}$ & $\begin{array}{r}57.06 \\
\pm 5.45\end{array}$ & $\begin{array}{r}7 \cdot 00 \\
\pm 4 \cdot 35\end{array}$ & $\begin{array}{r}6 \cdot 73 \\
\pm 2 \cdot 89\end{array}$ & $\begin{array}{r}5.75 \\
\pm 2.76\end{array}$ & $\begin{array}{r}85.05 \\
\pm 12.49\end{array}$ \\
\hline $\begin{array}{l}\text { Mean } \\
\text { S.D. } \\
\end{array}$ & $\begin{array}{r}49 \cdot 61 \\
\pm 3.97 \\
\end{array}$ & $\begin{array}{r}56 \cdot 32 \\
\pm 4 \cdot 23 \\
\end{array}$ & $\begin{array}{r}7.59 \\
\pm 1.89 \\
\end{array}$ & $\begin{array}{r}7 \cdot 16 \\
\pm 2 \cdot 87\end{array}$ & $\begin{array}{r}6 \cdot 76 \\
\pm 2 \cdot 88\end{array}$ & $\begin{array}{r}94.52 \\
\pm 6.36\end{array}$ \\
\hline $\mathbf{P}$ & $>0.8$ & $>0.7$ & $>0.6$ & $>0.6$ & $>0.2$ & $<0.01$ \\
\hline
\end{tabular}


control subjects. Similarly, the amplitude of the afferent volley was the same in the two groups. No difference was found between the two groups in muscle action potential amplitude with stimulation at the ankle, but with stimulation at the knee there was a tendency for the amplitude to be smaller in the lead workers than in control subjects (Table II). There was, however, a wide scatter of values and the difference did not reach statistical significance. To eliminate the difference in absolute amplitude the value after stimulation at the knee can be expressed as a percentage of that following stimulation at the ankle. When this was done for the control subjects the ratio was $94.5 \%$ (S.D. 6.4), whereas in the lead workers the tendency for amplitude to be lower following stimulation at the knee was accentuated and the ratio was $85.1 \%$ (S.D. 12.5), a highly significant difference $(P<0.01)$. The number of subjects in each group in whom this ratio was over $85 \%$ and in whom it was less is shown in Table III. It can be seen that smaller values were much more frequent among the lead workers.

TABLE III.-Ratio of Muscle Action Potential Amplitude following Stimulation at Knee and Ankle in Control Sabjects and Lead Workers

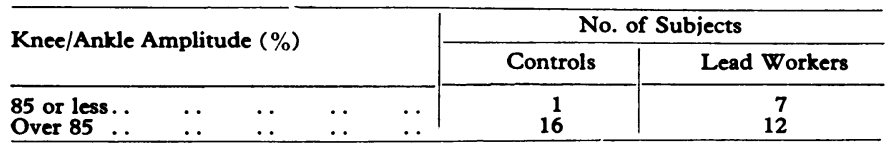

There is thus evidence of an abnormality of peripheral nerve function in some of the lead workers. It seemed possible that the development of this abnormality might relate to the duration of exposure, to the blood lead level, or to the degree of anaemia present. There did appear to be some association between abnormal electrical findings, a low haemoglobin value; and length of exposure to lead, but the number of observations was too small to draw any firm conclusion (Table IV). On the other hand, there did not appear to be any association between the electrical findings and the blood lead levels, though these indicated exposure to lead in all, which was excessive in 13 of the 19 men. block in conduction in some fibres between the two electrodes. Whatever the underlying nerve pathology there seems to be a minimal conduction defect in some of the lead workers. The preservation of normal maximal conduction velocity in our subjects must mean that not all of the largest fibres are affected or that the pathological changes are confined to the smaller fibres.

Subclinical peripheral nerve damage has previously been shown in patients suffering from certain other conditions such as diabetes (Mulder, Lambert, Bastron, and Sprague, 1961; Skillman, Johnson, Hamwi, and Driskill, 1961), renal failure (Preswick and Jeremy, 1964), alcoholism (Mawdsley and Mayer, 1965), and some genetic disorders (Dyck, Lambert, and Mulder, 1963; Earl, Fullerton, Wakefield, and Schutta, 1964).

The evidence we have obtained indicates that exposure to lead may give rise to peripheral nerve fibre damage. Some relationship was found between peripheral nerve damage, the length of exposure to lead, and the presence of anaemia, but there was little relationship with the blood lead level. In this respect the neuropathy behaved like the anaemia of leadpoisoning, which other workers have found to correlate poorly with the blood lead level (Williams, 1966).

Medical supervision has resulted in a great reduction in the occupational hazard faced by lead workers. Current practice utilizes regular haemoglobin and blood lead estimations to detect unacceptable levels of exposure in those at risk (B.M.F., 1968). The lead workers in the present survey had excessive exposure to lead, 13 of the 19 having blood lead values above $80 \mu \mathrm{g} . / 100 \mathrm{ml}$. and 9 of the 19 having haemoglobin values below $13 \mathrm{~g} . / 100 \mathrm{ml}$. One worker had undoubted symptoms of lead-poisoning - that is, colic-but all the subjects were free of neurological symptoms or signs. In some of these men, however, minimal nerve damage has been shown to exist by means of a sensitive electrophysiological technique. Only one group of workers has so far been studied and it is not yet known if minimal nerve damage can occur in workers exposed to concentrations of lead which are currently considered to be acceptable.

TABLE IV.-Peripheral Nerve Findings in Relation to Blood Lead, Haemoglobin Concentration, and Duration of Exposure in Lead Workers.

\begin{tabular}{|c|c|c|c|c|c|c|c|c|c|}
\hline \multirow{2}{*}{$\begin{array}{c}\text { Knee/Ankle } \\
\text { Amplitude (\%) }\end{array}$} & \multicolumn{3}{|c|}{ Blood Lead $(\mu \mathrm{g} . / 100 \mathrm{ml})}$. & \multicolumn{3}{|c|}{ Haemoglobin $-(\mathrm{g} . / 100 \mathrm{ml})}$. & \multicolumn{3}{|c|}{ Duration of Exposure in Months } \\
\hline & Over 80 & 80 or Less & Total & Less Than 13 & Over 13 & Total & 12 or Over & Less Than 12 & Total \\
\hline $\begin{array}{l}85 \text { or less } \\
\text { Over } 85\end{array}$ & $\begin{array}{l}4(57) \\
9(75)\end{array}$ & $\begin{array}{l}3(43) \\
3(25)\end{array}$ & $\begin{array}{r}7(100) \\
12(100)\end{array}$ & $\begin{array}{l}5(71) \\
4(33)\end{array}$ & $\begin{array}{l}2(29) \\
8(67)\end{array}$ & $\begin{array}{r}7 \cdot(100) \\
12 \cdot(100)\end{array}$ & $\begin{array}{l}5(71) \\
5(42)\end{array}$ & $\begin{array}{l}2(29) \\
7(58)\end{array}$ & $\begin{array}{r}7(100) \\
12(100)\end{array}$ \\
\hline
\end{tabular}

Percentages in parentheses.

\section{Discussion}

Maximal motor conduction velocity was thus normal in the group of workers exposed to lead. Nevertheless, the ratio of the amplitude of the muscle action potential following stimulation of the lateral popliteal nerve at the knee and at the ankle was in some instances smaller than that in control subjects. The most likely explanation for this finding is that conduction was slowed in some nerve fibres, causing dispersal of the muscle action potential, some of this occurring between the two stimulating cathodes. Alternatively there might be a
It seems likely that modern techniques will be able to demonstrate minimal degrees of damage due to a variety of toxic substances. In relation to lead, in the absence of clinical effects, it is unlikely that this will necessitate any significant change in the currently accepted standards, but the evidence suggests that the present standards represent minimal levels of safety and that any lowering of these might be unwise.

We would like to acknowledge the assistance of the technical staff of the medical laboratory of the Factory Inspectorate for the pathological investigations performed.
Bergamini, V. and Sibour; F. (1960). Rivista di Patologia Nervosa $e$ Mentale, $\mathbf{8 1}, 415$.

British Medical fournal, 1968, 4, 501.

Delwaide, P. J., and Chantraine, A. (1965). In Proceedings of 6th International Congress of Electroencephalography and Clinical Neurophysiology, p. 643. Vienna, Wiener Medizinische Akademie für ärztliche Fortbildung.

Department of Employment and Productivity (1968). Annual Report of H.M. Chief Inspector of Factories 1967. (Cmnd. 3745.) London, H.M.S.O.

Dyck, P. J., Lambert, E. H., and Mulder, D. W. (1963). Neurology (Minneapolis), 13,1.

Earl, C. I., Fullerton, P. M., Wakefield, C. S., and Schutta, H. S. (1964). Quarterly fournal of Medicine, 33, 481.

Fullerton, P. M. (1966). Fournal of Neuropathology and Experimental Neurology, 25, 214.

Fullerton, P. M. (1969). Proceedings of the Royal Society of Medicine, 62, 201 .
Gilliatt, R. W., Goodman, H. V., and Willison. R. G. (1961). fournal of Neurology, Neurosurgery and Psychiatry, 24, 305 .

Gombault, M. (1880). Archives de Neurologie, 1, 11.

Lloyd Davies, T. A. (1965). In Annual Report of H.M. Chief Inspector of Factories on Industrial Health 1965. (Cmnd. 3081), p. 23. London, H.M.S.O

Mawdsley, C., and Mayer, R. F. (1965). Brain, 88, 335.

Mulder, D. W., Lambert, E. H., Bastron, J. A., and Sprague, R. G. (1961). Neurology (Minneapolis), 11, 275.

Preswick, G., and Jeremy, D. (1964). Lancet, 2, 731.

Sessa, T., Ferrari, E., and d'Amato, C. C. (1965). Folia Medica (Napoli), 48, 658.

Simpson, I. A., Seaton, D. A., and Adams, J. F. (1964). Fournal of Neurology, Neurosurgery and Psychiatry, 27, 536. Skillman, T. G., Johnson, E. W., Hamwi, G. J., and Driskill, H. J.

Williams, M. K. (1966). British Fournal of Industrial Medicine, 23, 105. 